Pengembangan Rekayasa dan Teknologi, Vol 14, No. 1, Juni 2018, pp 5-9

p-ISSN: 1410-9840 \& e-ISSN: 2580-8850

http://journals.usm.ac.id/index.php/jprt/index

\title{
RASPBERRY PI DENGAN MODUL KAMERA DAN MOTION SENSOR SEBAGAI SOLUSI CCTV LAB FTIK UNIV. SEMARANG
}

\author{
Basworo Ardi Pramono ${ }^{1}$, Aria Hendrawan ${ }^{2}$, April Firman Daru ${ }^{3}$ \\ 1, 2, dan 3 Fakultas Teknologi Informasi dan Komunikasi, Universitas Semarang \\ ${ }^{1}$ basworo@usm.ac.id, ${ }^{2}$ aria@usm.ac.id, ${ }^{3}$ firman@usm.ac.id
}

\begin{abstract}
Monitoring of place / room in work is an important matter, where with the presence of CCTV monitors we can see the condition of a place with the help of surveillance cameras (CCTV). During this time for CCTV recording using DVR (Digital Video Recording) where these devices tend to be expensive and do not reach all circles. What's more if CCTV records continuously 24 hours a day for 1 month, of course it must provide a large hard disk space capacity.

The FTIK Lab Room became the object of research where using raspberry pi devices with camera modules and motion detection sensors where the Mini Raspberry Pi PC device will only record the condition of the room only when a motion is detected in the FTIK Lab room. Raspberry pi itself is a mini computer, Raspberry operating system can vary, one of which is Linux Debian which has been packaged. It is expected to reduce the burden of storage media. The use of Raspberry Pi in terms of monitoring / monitoring of a place or room requires a cheap and effective cost in utilization.
\end{abstract}

Keywords: supervision, raspberry pi, motion detection

\begin{abstract}
Abstrak
Pengawasan tempat/ruangan dalam pekerjaan merupakan hal penting, dimana dengan adanya CCTV pemantau kita bisa melihat kondisi suatu tempat dengan bantuan kamera pemantau (CCTV). Selama ini untuk perekaman CCTV mengunakan DVR (Digital Video Recording) dimana perangkat ini cenderung mahal dan belum menjangkau semua kalangan. Terlebih lagi jika CCTV merekam secara terus menerus 24 jam sehari selama 1 bulan, tentu harus menyediakan kapasitas ruang harddisk yang besar.

Ruang Lab FTIK menjadi objek penelitian dimana mengunakan perangkat raspberry pi dengan modul kamera dan sensor motion detection dimana perangkat PC Mini Raspberry Pi hanya akan merekam kondisi ruangan hanya pada saat terdeteksi suatu gerakan pada ruang Lab FTIK. Raspberry pi sendiri adalah sebuah komputer mini, sistem operasi Raspberry bisa bermacam-macam, salah satunya adalah Linux Debian yang telah dipaket minikan. Dengan itu diharapkan mampu mengurangi beban media penyimpanan. Penggunaan Raspberry Pi dalam hal pengawasan/monitoring tempat atau ruangan memerlukan biaya yang murah dan efektif dalam pendayagunaan.
\end{abstract}

Kata Kunci : pengawasan, raspberry pi, motion detection

\section{Pendahuluan}

Inovasi di era masa kini di bidang multimedia salah satunya adalah penggunaan kamera. Pada awal kemunculannya kamera hanya digunakan untuk mengabadikan momen-momen penting, kemudian munculah camcorder yang memiliki keunggulan dibandingkan kamera yaitu, objek yang ditangkap berupa gambar bergerak atau film. Kemajuan teknologi juga melahirkan sistem monitoring dengan menggunakan Closed Circuit Television (CCTV) yang merupakan seperangkat penangkap citra digital berupa gambar atau video yang terdiri atas kamera dan display (dapat berupa monitor atau televisi). Umumnya perangkat ini diaplikasikan pada jaringan private dan tertutup untuk publik sehingga tidak dapat diakses secara bebas kecuali oleh pihak-pihak yang memiliki otoritas. Penggunaan perangkat ini dapat mempermudah dalam memantau situasi dan kondisi baik didalam maupun diluar ruangan, sehingga dapat mencegah terjadinya suatu tindakan kejahatan.

Selain itu inovasi dibidang komputer yang sangat pesat ini memacu perkembangan komputer dari zaman ke zaman yang semakin canggih, dari yang ukurannya besar sampai kecil. Salah satu hasil dari perkembangan komputer adalah raspberry pi. Raspberry pi merupakan komputer dengan ukuran kecil, ukurannya yang tidak lebih besar dari kartu kredit, dengan konsumsi daya rendah yaitu sebesar 5V. Karena itulah raspberry pi mulai banyak digunakan dalam proyek dan penelitian teknologi. Teknologi pada Raspberry pi 
sendiri sudah mendukung berbagai macam perangkat keras untuk berbagai proyek dan penelitian, salah satunya ialah kamera untuk mendukung proyek pembuatan CCTV. Selama ini, CCTV dan IP Kamera menggunakan NVR (Network Video Recorder) sebagai server dan perangkat penyimpanan. Namun, harga perangkat NVR dan IP Kamera yang cenderung mahal belum terjangkau semua kalangan.

Ruang lab FTIK menjadi objek penelitian dimana mengunakan perangkat raspberry pi dengan modul kamera dan sensor motion detection dimana perangkat pc raspberry hanya akan merekam kondisi ruangan hanya pada saat terdeteksi gerakan pada ruang lab.

System CCTV konvensional selalu dalam kondisi merekam gambar dalam ruangan 24 jam sehari, bahkan pada saat ruangan tidak digunakan / kosong cctv akan tetap merekam. hal ini menjadi pemborosan dalam hal data video. Hal ini yang melatarbelakangi sehingga dapat diambil suatu solusi dimana cctv hanya akan merekam/ recording dimana pada saat ruang digunakan/ dipakai.

Pada lab FTIK USM terdapat cctv yang terus merekam keadaan ruangan 24 jam nonstop, hal ini mengakibatkan pemborosan ruang penyimpanan di hard disk. Penelitian dengan judul "Raspberry pi dengan modul kamera dan motion sensor sebagai solusi CCTV Lab FTIK USM" diharapkan dapat menjadi solusi untuk mengurangi pemborosan ruang penyimpanan di hard disk, karena Raspbeery pi hanya akan merekam pada saat terjadi gerakan di ruang Lab.

\section{KAJIAN PUSTAKA}

\subsection{Sejarah}

Raspberry Piadalah sebuah perangkat komputer seukuran kartu kredit, benar-benar praktis dan harganya di bawah $£ 30$. Sistem operasinya ditanam pada sebuah SD Flash Card, yang menjadikannya sangat mudah untuk diganti dan ditukar. Potensinya luar biasa, dari yang sudah maupun belum pernah dieksplorasi, tetapi telah diuji sebagai multimedia player dengan kemampuan streaming, sebagai perangkat game machine, internet browsing dan sebagai mainboard pengembangan hardware. Hal tersebut memungkinkan perangkat ini digunakan sebagai perangkat pendidikan bagi orang-orang dari segala usia dan tingkat keterampilan. Minat pada perangkat Raspberry $\mathrm{Pi}$ sangat luar biasa dan telah jauh melebihi harapan. Profesional IT, ahli elektronik dan pendatang baru semua bersemangat untuk 'meletakkan' tangan mereka pada perangkat kecil ini dan semua orang setuju, perangkat ini akan menjadi besar dan semakin berkembang
(Jaseman dan Meltwater dalam Majalah MagPi, $2012: 3)$.

Raspberry Pi (RasPi) merupakan sebuah Single Board Computer (SBC) yang memiliki ukuran sebesar kartu Kredit, Raspberry Pi ini merupakan sebuah komputer mini yang dikembangkan oleh Y ayasan Raspberry Pi yang bertempat di UK (United Kingdom). Pada awalnya Raspberry Pi ini dikembangkan untuk memicu proses pengajaran ilmu komputer dasar di sekolah - sekolah dengan biaya yang minim (http://www.raspberrypi.org).

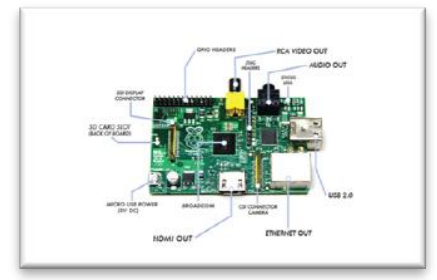

Gambar 2.1 Raspberry Pi

\subsection{Raspbian}

Raspbian adalah sistem operasi bebas berbasis Debian GNU / Linux dan dioptimalkan untuk perangkat keras Raspberry Pi (arsitektur prosesor arm). Raspbian dilengkapi dengan lebih dari 35.000 paket, atau perangkat lunak pre- compiled paket dalam format yang bagus untuk kemudahan instalasi pada Raspberry Pi. Awal di rilis sejak Juni 2012, menjadi distribusi yang terus aktif dikembangkan dengan penekanan pada peningkatan stabilitas dan kinerja sebanyak mungkin. Meskipun Debian menghasilkan distribusi untuk arsitektur lengan, Raspbian hanya kompatibel dengan versi yang lebih baru dari yang digunakan pada Raspberry Pi (ARMv7 CPU-A dan vs Raspberry Pi ARMv6 CPU yang lebih tinggi). (http://www.raspberrypi.org/download)

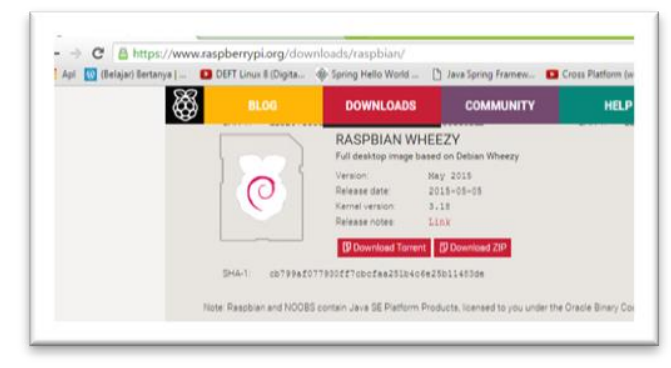

Gambar 2.2 Download Raspbian Wheezy

\subsection{CCTV}

(Closed Circuit Television) adalah sistem kamera pengawas yang menggunakan sinyal tertutup (closed circuit). CCTV digunakan untuk mengawasi suatu area yang dianggap penting atau rawan, mengingat makin banyaknya tindak kejahatan yang sangat sangat merugikan. 
Pengembangan Rekayasa dan Teknologi, Vol 14, No. 1, Juni 2018, pp 5-9

p-ISSN: $1410-9840$ \& e-ISSN: $2580-8850$

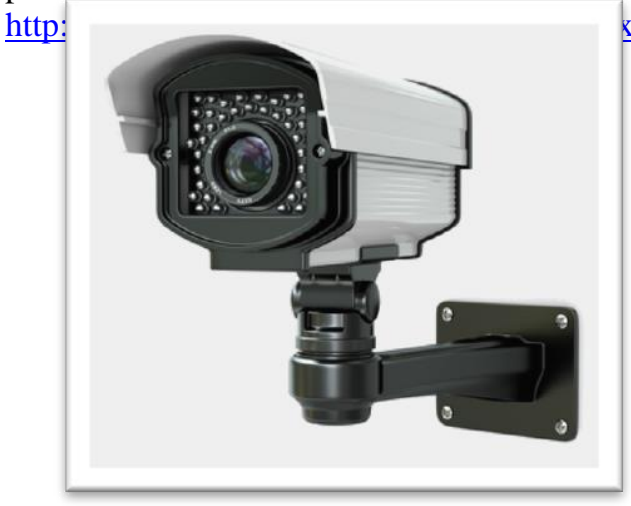

Gambar 2.3 CCTV

\subsection{PIR (Passive Infrared) Sensor}

Sensor electronic yang mendeteksi radiasi inframerah dari suatu objek sesuai dengan jarak tertentu. Sensor PIR bersifat passif, dimana sensor ini tidak memancarkan sinar infra merah tetapi hanya menerima radiasi sinar infra merah dari luar.

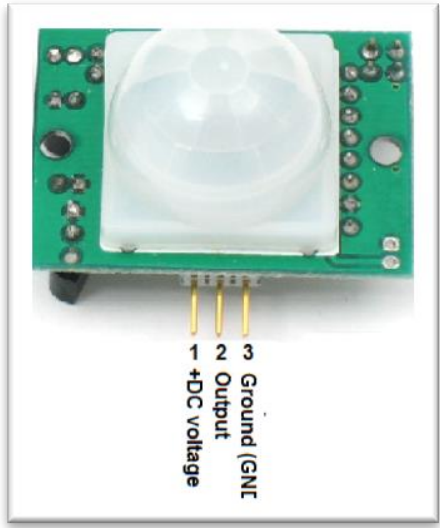

Gambar 2.4 PIR Sensor

\subsection{Modul Camera Raspberry Pi}

Modul kamera bawaan dari Raspberry Pi biasa digunakan untuk merekam video dengan High Definition. Untuk mengkoneksikannya modul kamera terdapat CSI port, berada dibelakang Ethernet port, dan membuat setingan kamera menjadi enable.

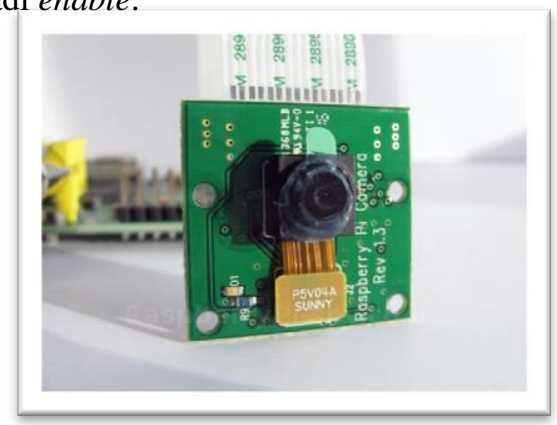

Gambar 2.5 Modul Camera

\section{III.METODE PENELITIAN}

Metode penelitian yang dikembangkan adalah waterfall, yaitu analisis kebutuhan, perancangan sistem, implementasi, pengujian sistem dan perawatan

Untuk mendapatkan hasil yang bagi penelitian ini, maka dibutuhkan data-data dan informasi untuk mendukung pembuatan laporan yang berasal dari sumber yang dapat dipertanggungjawabkan Metode Pengumpulan Data

\section{a) Data Primer}

Data primer yaitu data atau keterangan yang diperoleh secara langsung dari pihak yang terlibat, yaitu berupa jawaban yang diperoleh langsung dari pihak-pihak terkait. Dalam pelaksanaan pengumpulan data ini, kami menggunakan metode yaitu:

1. Metode Dokumentasi, yaitu metode pengumpulan data melalui pemahaman literatur maupun buku dan juga melalui internet sebagai acuan untuk menentukan landasan teori..

2. Metode Observasi atau pengamatan, yaitu pengumpulan data dengan melakukan pengamatan dan pencatatan secara langsung mengenai hal-hal yang diselidiki.

\section{b) Data Sekunder}

Data yang diperoleh dengan cara melaksanakan studi kepustakaan dari catatan literatur dan kepustakaan yang berhubungan dengan objek penelitian.

\section{Lokasi Penelitian}

Yang menjadi lokasi/objek penelitian adalah laboratorium Lanjut FTIK-USM, yang berada di Gedung M lantai 2. Lokasi/Objek ini dipilih peneliti karena tata letak infrastruktur ruang yang tertutup rapat dan minim jendela ini untuk mengukur efektifitas sensor agar tidak ada ganguan dari luar.

\section{IV.HASIl DAN PEMBAHASAN}

\subsection{Kebutuhan Perangkat Keras dan Lunak}

Perangkat keras yang digunakan untuk percobaan dan mengolah data dalam penelitian ini berupa sebuah raspi dan pc.

\subsubsection{Implementasi Perangkat Keras}

Tabel 4.1 Perangkat Keras yang digunakan

\begin{tabular}{|l|l|l|l|}
\hline No & Spesifikasi & Raspberry Pi B+ & PC Asus \\
\hline 1 & Prosesor & $700 \mathrm{MHz}$ ARM1176JZF-S core & $2 \mathrm{Gh}$ i5 \\
\hline 2 & Memori & $512 \mathrm{MB}$ (shared with GPU) & $8 \mathrm{G}$ \\
\hline 3 & hard disk & $8 \mathrm{~Gb}$ & $500 \mathrm{G}$ \\
\hline 4 & video card & Broadcom VideoCore IV & $\begin{array}{l}\text { Nvidia } \\
\text { Gforce }\end{array}$ \\
\hline
\end{tabular}




\subsubsection{Implementasi Perangkat Lunak}

Tabel 4.2 Perangkat Lunak yang digunakan

\begin{tabular}{|c|l|l|c|}
\hline $\begin{array}{l}\text { N } \\
\text { o }\end{array}$ & Perangkat & Sistem Operasi & $\begin{array}{c}\text { Bahasa } \\
\text { pemrograman }\end{array}$ \\
\hline 1 & Raspberry Pi tipe B & Rasbian Wheesy & Python 3 \\
\hline 2 & Note book Asus & Windows 8 64 bit & \\
\hline
\end{tabular}

\subsection{Desain Perancangan System}

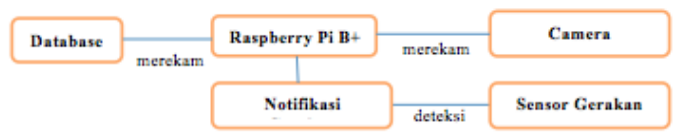

Gambar 4.3 Desain Perancangan Sistem

System cctv mengunakan Raspberry pi sebagai komponen atau server utama. Kamera (pi camera) digunakan untuk merekam semua kejadian yang ada di laboratorium. Raspberry $\mathrm{Pi}$ yang dilengkapi dengan sensor gerakan berdasarkan perubahan radiasi infra merah yang berada didekat sensor tersebut. Jika sensor mendeteksi gerakan maka raspberry pi akan mengirimkan notifikasi ke computer klien dan secara bersamaan akan merekam video dan menyimpannya ke memori database.

\subsection{Implementasi Sistem}

4.3.1 Instalasi Sistem kedalam Raspberry

Board raspberry pi model B sudah dilengkapi dengan 4 buah port usb, 1 port HDMI, video komposit RCA, port audio 3.5 $\mathrm{mm}$, port SD card, port RJ45, dan 40 pin.

Langkah instalasi:

1. Download Rasbian versi terbaru di link : https://www.raspberrypi.org/downloads/ raspbian/

2. Gunakan win32diskimager(windows) dan Raspberry pi SD Card Builder (mac) untuk menginstall OS Rasbian Wheesy ke dalam modul memori.

3. Hubungkan semua peralatan (LCD HDMI, keyboard, mouse) kedalam perangkat Raspberry Pi. Masuk dengan menggunakan akun root, username "pi" dan password "raspberry".

\subsubsection{Pengaturan kamera pada Raspberry Pi}

1. Masukkan modul kamera pada Raspberry pi.
2. Masuk ke bagian option pegaturan di Rasbian, kemudian pilih "enable camera".

3. Uji coba camera dengan mengunakan script Python3.

4.3.3 Pengaturan Sensor untuk mendeteksi Gerakan

1. Gunakan kabel jumper Female-female untuk menyambungkan dengan Raspberry.

2. Pin vec sensor dihubung dengan pin vec (no 1)raspi, pin ground sensor dihubungkan dengan pin ground(no 3), dan untuk pin input output sensor dihubungkan dengan pin no 4 Raspberry $\mathrm{Pi}$.

4.3.4 Recording berdasarkan input dari sensor

\subsection{Pengujian Sistem}

Pengujian merupakan hal terpenting yang bertujuan untuk menemukan kesalahankesalahan atau kekurangan kekurangan pada perangkat lunak yang akan diuji. Pengujian bermaksud untuk mengetahui perangkat lunak yang dibuat sudah memenuhi kriteria yang sesuai dengan tujuan perancangan perangkat lunak tersebut.

Tabel 4.3 Pengujian Raspberry Pi

\begin{tabular}{|c|c|c|c|}
\hline No & Kelas Uji & Butir Uji & Hasil Uji \\
\hline 1 & $\begin{array}{l}\text { Kontrol } \\
\text { kamera } \\
\text { raspberry }\end{array}$ & $\begin{array}{l}\text { Perangkat kamera bisa } \\
\text { dikontrol dengan raspberry }\end{array}$ & berhasil \\
\hline 2 & $\begin{array}{l}\text { Kontrol } \\
\text { sensor }\end{array}$ & $\begin{array}{llr}\text { perangkat } & \text { sensor } & \text { dapat } \\
\text { dikontrol } & \text { dan } & \text { mampu } \\
\text { mendeteksi } & & \end{array}$ & berhasil \\
\hline 3 & $\begin{array}{l}\text { Pengambila } \\
\text { n gambar }\end{array}$ & $\begin{array}{l}\text { pengambilan gambar } \\
\text { dilakukan oleh kamera }\end{array}$ & berhasil \\
\hline 4 & $\begin{array}{l}\text { pengujian } \\
\text { perekaman }\end{array}$ & $\begin{array}{lr}\text { perekaman } & \text { dilakukan } \\
\text { berdasarkan } & \text { hasil deteksi } \\
\text { dari sensor } & \end{array}$ & berhasil \\
\hline
\end{tabular}

Tabel 4.4 Pengujian jarak

\begin{tabular}{|c|c|}
\hline $\begin{array}{l}\text { Pengujian sensor berdasarkan } \\
\text { jarak }\end{array}$ & $\begin{array}{l}\text { Deteksi } \\
\text { sensor }\end{array}$ \\
\hline 1 meter & aktif \\
\hline 2 meter & aktif \\
\hline 3 meter & aktif \\
\hline 4 meter & tidak aktif \\
\hline 5 meter & tidak aktif \\
\hline
\end{tabular}

\subsection{Perawatan Sistem.}

Perawatan adalah segala kegiatan yang bertujuan untuk menjaga peralatan dalam kondisi baik, proses perawatan meliputi 
Pengembangan Rekayasa dan Teknologi, Vol 14, No. 1, Juni 2018, pp 5-9

p-ISSN: $1410-9840$ \& e-ISSN: $2580-8850$

http://journals.usm.ac.id/index.php/jprt/index

pengukuran, penggantian, penyesuaian dan perbaikan.

1. Perbaikan peralatan yang beroperasi tidak normal, identifikasi penyebab kerusakan, penggantian komponen/ modul yang rusak, mengatur kembali control, dan juga update system linux yang ada.

2. Mencegah terjadinya kerusakan selama operasi berlangsung, dilakukannya pergantian komponen terjadwal sesuai dengan estimasi umur peralatan.

\section{SimpUlan DAN SARAN}

Simpulan :

1. Sensor hanya dapat maksimal pada jarak 3 meter

2. Raspberry pi, camera modul dan sensor mampu mewujudkan cctv untuk keamanan ruang yang baik.

3. Hasil perekaman video dalam format h264, format kompresi definisi tinggi dengan ukuran separuh format kompresi DVD.

Saran :

1. Kedepannya dapat dikembangkan lagi dengan menambahkan kamera yang bersifat aktif, yang mampu mengikuti pergerakan orang.

2. Kualitas kamera kedepannya dapat ditingkatkan lagi.

\section{DAFTAR PUSTAKA}

[1] Beazly, David. 2013. Phyton Cookbook, O Reilly Media.

[2] http://www.raspberrypi.org/

[3] http://elinux.org/RPi Tutorials

[4] Tandy. Mei 2012.The MagPi issue.

[5] https://eltechs.com/raspbian-and-otherraspberry-pi-software/

[6] http://jip.polinema.ac.id/ojs3/index.php/jip/art icle/view/138/125

[7] Dinata, Andi. 2017. Physical Computing dengan Raspberry Pi. Jakarta : Kompas Gramedia Building 